\title{
Al-Bunayya, una ciudad fortificada benimerín en la costa norte del estrecho de Gibraltar (1282-1375)
}

Al-Bunayya, a fortified Marinid city on the northern coast of the strait of Gibraltar (1282$1375 \mathrm{AD})$

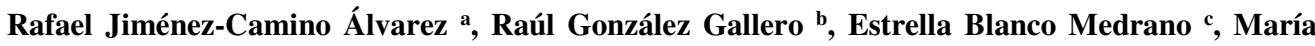 \\ Ángeles Ramos Martín d, Aurélie Simone Eïd ${ }^{\mathrm{e}}$ \\ Ayuntamiento de Algeciras, Cádiz, Spain \\ a cultura.arqueologia@algeciras.es; ${ }^{b}$ raulgallero@hotmail.com; ${ }^{c}$ estrella-blanco@hotmail.es; ${ }^{\mathrm{d}}$ ramosmartinma@hotmail.com; \\ e aureleid@gmail.com
}

\begin{abstract}
This article presents the results of the archaeological investigation carried out between 2017 and 2018 by Algeciras City Council in al-Bunayya (1282-1375), the only city founded by the Marinid dynasty in al-Andalus, after recent research revealed its true location. Until then, the site of the city had been at-

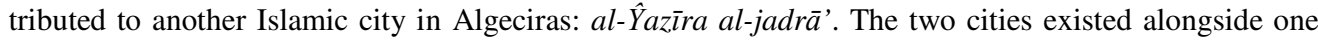
another from the end of the Middle Ages, until they were destroyed by the Nasrids in 1375 or 1379 and subsequently abandoned.

The medina's defences comprised a wall protected by two lines of concentric barbicans and a third section which may have formed part of the entrance to one of the city gates. At least three phases of construction have been identified: the first coincides with the founding of the city by the Marinid sultan Abū Yūsuf (1282-1285), when the wall and the first barbican were built from rammed earth, a technique used in most Marinid urban settlements. The second phase (1285-1344) may be linked to Nasrid refurbishments, which covered or substituted the former rammed earth walls of the towers with walls made from layers of stone masonry and filled with rubble masonry, reflecting the customary methods used to refurbish fortifications on the border with Castile. The third phase (1344-1369) may be attributed to the time of the Castilian conquest due to the presence of stonemasons' marks, and involved the construction of a sloping barbican using stone and rubble masonry.
\end{abstract}

Keywords: Marinid, Nasrid, rammed earth, urban fortification.

\section{Introducción}

La ciudad de al-Bunayya o al-Binya fue fundada por el sultán meriní Abū Yūsuf como centro de operaciones para realizar la $\hat{y} i h \bar{a} d$ en suelo andalusí. Funcionó como un campamento militar fortificado e independiente de la antigua medina

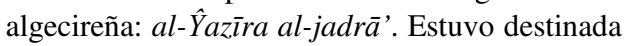
al alojamiento, tanto de los Voluntarios de la $\mathrm{Fe}$ y su impedimenta, como del emir que debía guiarlos, aspecto este último que justificó la construcción de un área palaciega en su interior (Tomassetti, Jiménez-Camino, 2012; JiménezCamino, 2016). Su fundación se encuadra históricamente en la denominada "Batalla del Estrecho", un conflicto internacional que enfrentó a castellanos, aragoneses, nazaríes y benimerines por el control de los puertos de la orilla norte del 
estrecho de Gibraltar (Algeciras, Tarifa y Gibraltar).

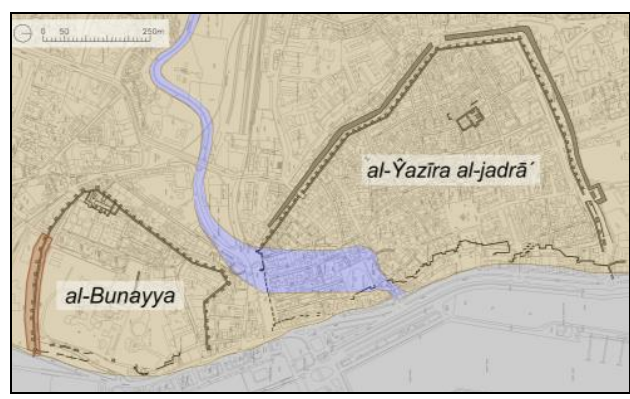

Fig. 1. Las dos medinas de Algeciras: al-Bunayya y alŶazira al-jadrā' (según Jiménez-Camino y Tomassetti, 2006 vs. Torremocha, Navarro y Salado, 1999), con la indicación de la parcela excavada (izqda., recuadro en rojo) y el río de la Miel.

Hasta hace muy poco se había errado en la localización de esta ciudad, creyéndola situada al norte del río de la Miel (a la derecha del cauce en la Fig. 1) y de un tamaño casi tres veces superior (Torremocha, Navarro, Salado, 1999). Posteriormente, hemos demostrado cómo varias fuentes medievales contemporáneas a los hechos recogen el testimonio de testigos a través de los cuáles se ha podido situar la ciudad al sur de ese río. Las diferentes excavaciones realizadas en uno y otro emplazamiento avalan sin ningún género de dudas esta nueva tesis (JiménezCamino, Tomassetti, 2006). También hemos podido demostrar cómo los restos del sistema defensivo, situados en el entorno de la Puerta de Gibraltar de la ciudad septentrional y ejecutados con mampostería y sillería isódoma, hasta ahora identificados como meriníes, son en realidad obra de Alfonso XI (Tomassetti, JiménezCamino, Perles, 2013).

Esta intervención arqueológica constituye una fase previa de un programa más ambicioso para el que tenemos autorizado un Proyecto General de Investigación, titulado "De Iulia Traducta a al-Bunayya. Topografía y evolución urbana de Algeciras entre época romana y bajomedieval", que pretende la continuación de las investigaciones y la musealización del yacimiento. El proyecto se co-financia a través del Fondo Social Europeo y el Ayuntamiento de Algeciras; y en el mismo participa la Universidad de Cádiz. En esta primera fase, la excavación se ha centrado en el tramo meridional de la fortificación (Fig. 1), en la parcela conocida como "Huerta del Carmen", donde se han llevado a cabo diez sondeos agrupados en tres sectores (Fig. 12).

\section{Fase I. Fundación del sistema defensivo (1282-1285): las fábricas encofradas}

Los primeros datos de esta excavación apuntan a que la muralla y la primera barbacana se construyeron, o bien cortando los niveles romanos (sector 3, sondeo 5), o bien excavando en el sustrato natural (sector 2, sondeo 3 ), con la peculiaridad de que la cimentación de la barbacana profundiza más que la de la muralla. Entre ambas estructuras se dispone una liza de entre 3 y $3,78 \mathrm{~m}$ de ancho, compactada sobre un nivel natural de cantos rodados (posible terraza fluvial). Cuando se ha podido examinar la base de estos muros, el encofrado, que originó un tapial monolítico, se ha levantado sobre una hilada de mampuestos. No se ha documentado ninguna fase medieval anterior al período comprendido entre finales del siglo XIII y el XIV, por lo que suponemos que tal y como nos traslada la Crónica de Alfonso X, la ciudad se fundó ex novo. El hecho de que cuando se ha identificado la fosa de fundación de la barbacana (sondeo 5), el nivel del pavimento haya desaparecido y que cuando el suelo aparece (sondeo 3) no se documente la fosa asociada a la construcción de la muralla y el antemuro, ha impedido comprobar una secuenciación entre ambos. Nuestra hipótesis es que son coetáneos.

Es interesante constatar que el antemuro contornea el trazado de las torres (Fig. 12), a diferencia de lo que se pensaba (Torremocha, 2004, p. 173, Fig. 6; Jiménez-Camino, 2016, p. 235, Fig. 3) y lo que ocurre con el de Fez, el único documentado en el ámbito de las nuevas fundaciones urbanas meriníes que, por el contrario, sigue un trazado lineal paralelo a la muralla (Pavón, 1996, 46). La forma de rodear a las torres, a partir de tramos ortogonales, es semejante a la seguida en la cerca almohade de Jerez (González, Aguilar, 2011, p. 55), pero distinta a la utilizada en la Sevilla almohade, en el tramo aún visible en la Macarena, donde los vértices se achaflanan. 
En cuanto a su envergadura, el ancho del antemuro es de 1,65 m, pero desconocemos el de la muralla, cuyo desarrollo se esconde bajo la valla perimetral del yacimiento. Muralla y barbacana están revestidas en su cara meridional (la exterior) con una capa de enlucido.

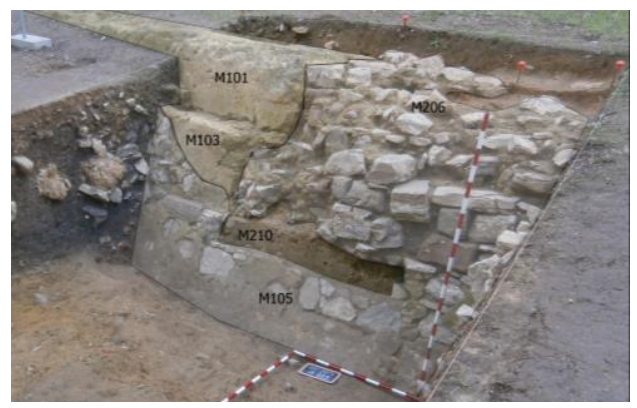

Fig. 2. Superposición de las obras de mampostería a las encofradas en el sector 1 (sondeos 1 y 2). Véase cómo toda la barbacana encofrada está forrada por la hoja de mampostería (M105) que sirve a su vez de horma para el relleno de calicanto (M206), que está sobre la tapia (M210).

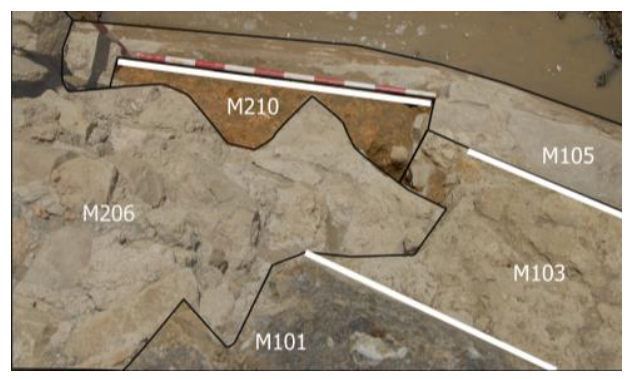

Fig. 3. Vista en planta del desplazamiento de los bloques de las tapias. Véase cómo la cara de M210 no confluye en un vértice con M103, ya que éste se ha deslizado, y nótese también el desplazamiento de la cara de M101 respecto a M103, que debían estar alineadas en origen.

En el sector 1, se ha podido documentar la superposición de las obras de mampostería a las encofradas evidenciando su posterioridad (Fig. 2). En la fase más antigua se identifican dos tramos de un muro que se unen en un vértice generado por un quiebro del trazado de la barbacana, sólo que no convergen a la misma altura (Fig. 3). El cajón inferior del tramo de 10 metros situado al oeste del vértice (M103) se halla desplazado $20 \mathrm{~cm}$ en dirección NE-SW con respecto al brazo situado al este (Fig. 4). El cajón superior del tramo occidental, de $78 \mathrm{~cm}$ de altura, también se halla desplazado otro tanto del infrayacente, además de encontrarse volcado hacia el norte. Una posible explicación para este fallo estructural, que generó un escalonamiento en los cajones del antemural, es que fuera originado por el seísmo que describimos en el apartado 4. No obstante, la diferente coloración de los tramos situados a un lado y otro del vértice puede responder a que pertenezcan a dos fases constructivas (M103 vs. M210). El escalón fue reparado posteriormente mediante la construcción del forro de mampostería ataluzado que también analizamos en el epígrafe 4 (Figs. 2-4).

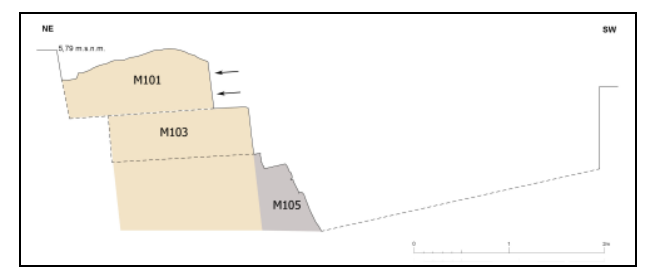

Fig. 4. Sección del desplazamiento del cajón superior de la barbacana (M101), producido posiblemente por el seísmo de 1356 y reparado posteriormente con un forro de mampostería (M105), en el sector 1.

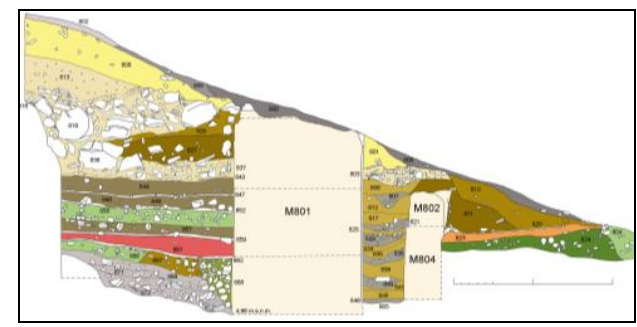

Fig. 5. Perfil este del sondeo 8. Barbacana M801 y pretil (M802 y M804) que dejan en medio la canalización (C801). Escala gráfica de $2 \mathrm{~m}$.

Entre esta barbacana y la de la primera línea se desarrolla otro tramo (M801; Figs. 5 y 12) del que hemos documentado $11,60 \mathrm{~m}$, con un ancho de 1,64 $\mathrm{m}$ y una altura máxima conservada de 2,60 m, que hemos descubierto en el sondeo 8 . Investigadores anteriores lo confundieron directamente con la primera línea defensiva (Torremocha Silva, 2004, p. 116). La anómala disposición en el sector central de la excavación de estos dos tramos concéntricos de antemuros 
encofrados, adelantados sobre la primera línea de antemural (M101 y M801; Fig. 12), nos ha llevado a plantear la posible existencia de un dispositivo de acceso a la ciudad con varios recodos, coincidente con el lugar que habíamos especulado como emplazamiento de una de las puertas de la medina, en un trabajo anterior (Tomassetti, Jiménez-Camino, 2012, p. 41). Esta barbacana tiene la peculiaridad de estar separada de la liza, que en este caso es un pavimento de cal, por una canalización con pretil realizado también con tapiales, pero de un ancho menor y ejecutado en dos fases (M802 y M804) (Fig. 5). En cuanto a la técnica de fabricación, hay que señalar que estaba realizada mediante medias agujas, al igual que el tramo de la barbacana exterior (M101). En este última, se ha podido documentar, además, el negativo de los clavos de madera de sección cuadrada sobre la huella de la aguja y el negativo cilíndrico de la cuerda que atirantaba el costal (Fig. 6). En general, estas agujas de sección rectangular tienen un largo de c. $65 \mathrm{~cm}$, están separadas entre sí de 42 a $63 \mathrm{~cm}$, tienen un ancho de 10-13 $\mathrm{cm} \mathrm{y,} \mathrm{con}$ mayor dificultad, por hallarse desaparecido el cajón superior, se ha comprobado que el alto ronda $10 \mathrm{~s} 7-9 \mathrm{~cm}$.

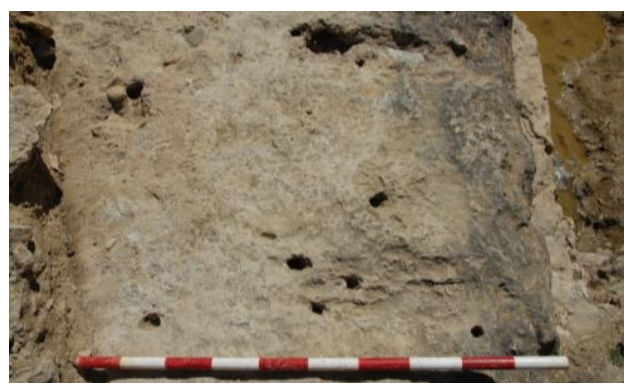

Fig. 6. Huella de los clavos en el negativo muy erosionado de las medias agujas (M101). Alrededor de éstas, negativos de las cuerdas que ataban los costales.

\section{Fase II. La reforma nazarí (1285-1344; con gran probabilidad entre 1312 y 1329)}

En este momento se produce un nuevo programa constructivo que sustituye las torres de la fase anterior, realizadas seguramente con tapiales, por bastiones macizos de ca. $5,40 \mathrm{~m}$ de lado levantados con muros perimetrales de mampos- tería rellenos al interior con calicanto; y se construye un nuevo pavimento de la liza con tierra apisonada. Para la erección de las torres, se empleó un encofrado no re-aprovechable formado por cuatro hojas: tres realizadas ex professo con mampostería concertada de piedra arenisca, ordenada por hiladas y ligada con argamasa, que trabados entre sí formaban una estructura en forma de "C" adosada a un cuarto muro: la misma muralla de hormigón reutilizada. Este cuadrilátero, cuyas esquinas exteriores se reforzaron con mampuestos algo más grandes y de un material diferente al resto (calcarenita), se fue rellenando con un vertido de calicanto para formar el núcleo a medida que se iban levantando los cajones. El hecho de que la torre aproveche la muralla para su construcción nos permite asegurar que aquella es posterior. Al menos en su lado este, se erigió sobre una zapata de cimentación que sobresalía $40 \mathrm{~cm}$ de la latitud de la fachada, para cuya inserción se abrió una zanja que cortó el pavimento de la fase anterior. La parte inferior del alzado presenta un pequeño zócalo de $75 \mathrm{~cm}$ de alto y $10 \mathrm{~cm}$ de grosor.

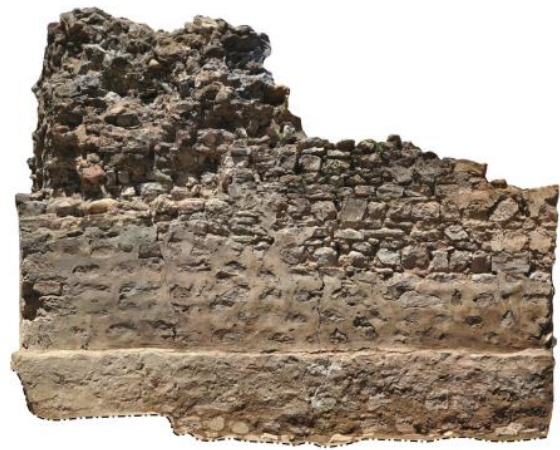

Fig. 7. Ortofotografía del lado este de la torre T4 que se erigió con calicanto entre hojas de mampostería.

De esta forma se han construido las únicas tres torres emergentes en la parcela (Fig. 12). Suponemos que las torres de tapial debían ocupar el mismo espacio que estas nuevas puesto que la barbacana de la fase anterior (M322) contornea a la torre T4 (Figs. 11 y 12). Por otro lado, y solo en el caso de esta torre, se ha comprobado como su núcleo está estratificado en tres niveles, los dos primeros realizados con un hormigón más fino y parecido al de la muralla y la barbacana, 
en el intermedio se observan además claramente las tongadas, que podrían responder a la antigua torre levantada con tapiales, que fue posteriormente chapada al exterior y a partir de cierta altura, por la reforma con mampostería y calicanto (Fig. 8). No obstante, no se observa una separación nítida entre el forro lateral y el núcleo supuestamente realizado con tapiales, debido quizás al picado de la cara de la antigua torre para una mejor trabazón del calicanto.

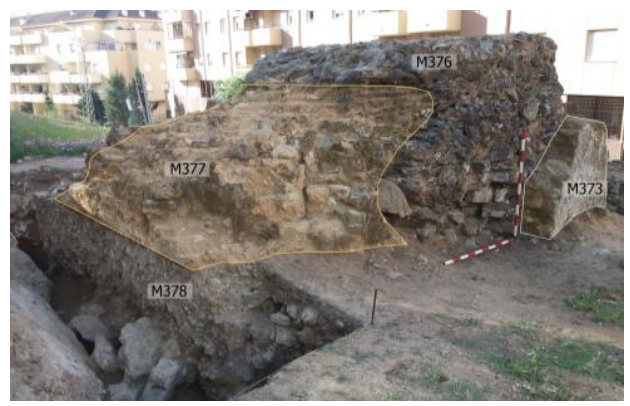

Fig. 8. Vista desde el noroeste de la torre T4. Antigua torre realizada con tapiales (M377 y M378) embutida dentro de la obra de calicanto (M376), a su vez realizada contra la hoja de mampostería (M373).

La cara externa de la torre y de la muralla fueron cubiertas por un mismo enlucido documentado incluso en la esquina que une ambos elementos. Éste, de unos $3 \mathrm{~mm}$ de grosor, es más fino y blanquecino que la capa de preparación, más gruesa $(15 \mathrm{~mm})$.

En algunos derrumbes de época contemporánea se han rescatado fragmentos paralelepípedos de mampostería y ladrillo, posteriormente enlucidos, pertenecientes a la merlatura.

En cuanto a la cronología, se ha comprobado que la construcción debió realizarse antes de la conquista cristiana de la ciudad, puesto que el pavimento de la liza que cubre la fosa de cimentación está amortizado por niveles castellanos, como delata la cerámica mudéjar del siglo XIV procedente de los centros productores de Sevilla (serie blanca y verde) y Paterna (serie monocroma blanca y "verde y morada"), por lo que la edificación de la torre es previa (JiménezCamino, et al., e.p.). La fábrica se diferencia nítidamente, además, de la empleada en las torres castellanas de la otra villa, cuyas hojas exteriores se erigieron con sillería isódoma marcada con signos lapidarios. Un breve análisis de la cerámica de la secuencia constructiva del sector 2, junto a la torre $\mathrm{T} 4$ puede leerse en Jiménez-Camino, et al., e.p.

La obra pertenece, por tanto, a una segunda fase de reformas, anterior a la ocupación castellana (1344) y posterior a la fundación meriní (1285), caracterizada ésta última por el uso de tapiales y a la que se asociaba el primer pavimento de la liza. En otro lugar, uno de nosotros ha explicado cómo el momento en el que este refuerzo pudo hacerse más necesario fue el período en el que la ciudad quedó aislada entre las villas de Tarifa y Gibraltar, tras la conquista de esta última en 1309 por Fernando IV. A partir de aquí, hubo un lapso en el que Algeciras quedó en manos de los sultanes nazaríes (1312-1329) (Jiménez-Camino, 2016, pp. 222, 263-268). Se ha comprobado como esta dinastía realizó, algo más tarde, bajo Muhammad $\mathrm{V}$, un programa de sustitución $\mathrm{y}$ chapado de las viejas defensas almohades de la frontera, que habían sido realizadas con tapiales, con obras de mampostería y calicanto (Acién, 1999), del que esta fortificación puede ser un precedente.

Previamente a estos trabajos se había planteado que las torres de este recinto eran del siglo IX (Torremocha, 2004, p. 117) o almorávides (Marcos, 2017, pp. 170-172, quien las había comparado con las de Amergo, en Marruecos).

\section{Fase III. La reforma castellana (1344-1369)}

El último programa constructivo, identificado ahora por primera vez, corresponde a la creación de una segunda línea de barbacana, concéntrica a la primera y a una distancia de c. $16 \mathrm{~m}$, en la que se aplica una importante innovación técnica. Ésta se realiza con la base en talud, forrando la ladera de la meseta a la que se adosa. Esta técnica, ya aplicada en fortificaciones realizadas con tapiales de época almohade, aparece en algunas obras supuestamente islámicas (ss. XIII-XIV) como el hisn Qartayanna, en San Roque (Cádiz) o la alcazaba de Antequera y se le ha atribuido un posible origen en Tierra Santa. También se ha documentado en defensas contemporáneas del 
área catalana y andaluza (la bibliografía de todo ello en Jiménez-Camino, 2016, pp. 246-249).

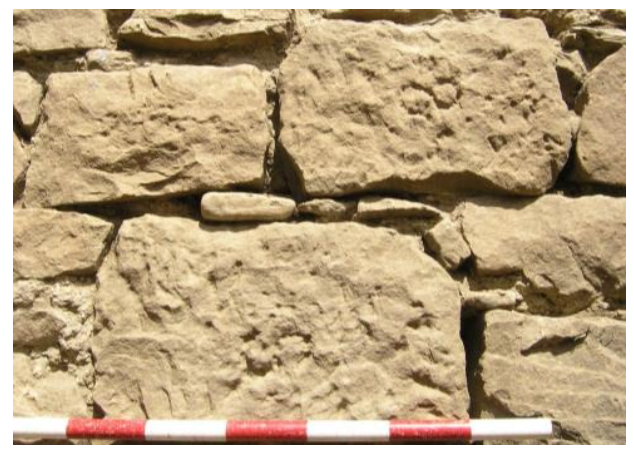

Fig. 9. Marcas de cantero castellanas sobre la barbacana ataluzada, en el sondeo 4. Símbolo de infinito (arriba) y "S" tumbada (abajo).

La falsabraga está fabricada con un núcleo de calicanto contenido entre la pendiente de la colina, por un lado, y la hoja ataluzada con fábrica de mampostería que tiene piezas concertadas, ordenadas por hiladas, enripiadas y alternadas con líneas de lajas. La principal diferencia con el aparejo de las torres nazaríes, que tienen parecido sistema constructivo, es el uso puntual de algunas piezas mejor escuadradas y en cuya superficie se observan las marcas del cincelado que está ausentes en la fase granadina y que permiten una ajustada datación de esta reforma, porque todas las así trabajadas están marcadas con signos lapidarios cristianos. Concretamente en el sondeo 4, en un paño de c. 2 × $2 \mathrm{~m}$ se han identificado cuatro sillarejos en los que se repiten dos tipos de signos (Fig. 9). Ello permite barajar una cronología similar a la del brazo del foso realizado con la misma técnica que rodea a la Puerta de Gibraltar, en la otra villa de Algeciras, la andalusí. Allí, los mampuestos también han sido signados con marcas de cantero y una inscripción circunscribe su datación al reinado de Alfonso XI (Tomassetti, Jiménez-Camino, Perles, 2013). Sin embargo, su documentación en la zona central del solar (sector 1), reparando una obra encofrada anterior que había sufrido un colapso posiblemente originado por un seísmo, tal y como vimos más arriba (Figs. 2-4), permite una datación más precisa, ya que dentro de la horquilla en que la fortificación estuvo funcio- nando se ha documentado un terremoto de gran magnitud, concretamente en 1356 (Gentil, 1989, pp. 105-112), cuando la ciudad se hallaba bajo la soberanía de Pedro I, lo que establecería un terminus post quem.

Esta excavación confirma las sospechas previas sobre la ausencia de foso en este tramo de la fortaleza. Nosotros pensamos que, de existir, debió circunscribirse exclusivamente a la zona de la puerta, contexto en el que es mencionado en la Crónica de Alfonso XI (Jiménez-Camino, 2016, pp. 253-254).

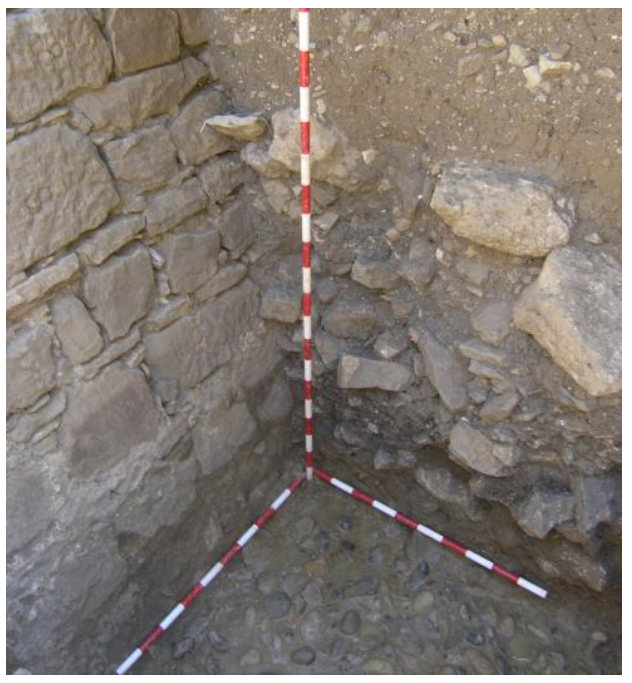

Fig. 10. Barbacana ataluzada en el sondeo 4.

Asociados a esta barbacana hemos hallado restos de la liza en diferentes puntos. Ésta se hallaba a una cota más baja que el tramo situado entre la muralla y la primera barbacana, por lo que las defensas estaban escalonadas, lo que seguramente justificó que el antemuro de la primera línea tuviera una cimentación más profunda que la muralla. En el sondeo 6, estaba compuesto por un nivel con cantos de río trabados con arcilla, en el sondeo 8, a esta preparación se le sobrepuso un pavimento de cal.

\section{Fase IV. El abandono nazarí (1375 o 1379)}

Al principio de su reinado, Enrique II, hijo del monarca que conquistó Algeciras, se hallaba imbuido en un conflicto sucesorio con el monarca portugués, coyuntura que aprovechó 
Muḥammad V para recuperar la ciudad. Sabemos por distintas fuentes que, poco después, los nazaríes la destruyeron en algún momento de finales del siglo XIV, aunque éstas no se ponen de acuerdo con la fecha. Lo cierto es que a partir de 1374 los nazaríes recuperaron Gibraltar, la última base peninsular meriní, y ambos hechos la destrucción de Algeciras y la restitución de Gibraltar, una posición más pequeña y fácilmente defendible- están posiblemente relacionados (Gómez de Avellaneda, 2018).

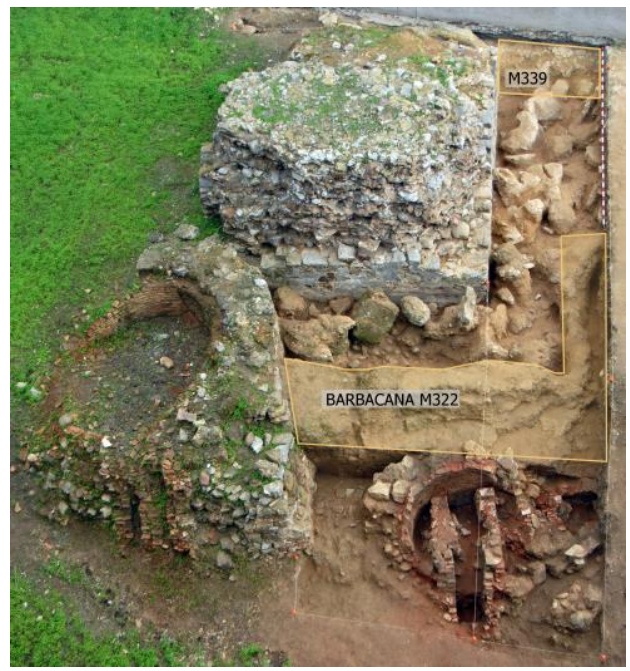

Fig. 11. Derrumbe de bloques de hormigón sobre la liza en el sondeo 3 y muralla (M339) volcada hacia intramuros.

En el sondeo 3 (sector 2), junto a la torre T4 se documentó un nivel de derrumbe de la muralla y la barbacana con grandes bloques de hormigón, datado en esta época. La muralla se hallaba volcada hacia el centro de la ciudad. En la parte excavada, no se documentó ningún indicio de destrucción sistemática, a diferencia de lo ocurrido en la otra medina de Algeciras (Torremocha, Navarro, Salado, 1999, pp. 158-162).

La compacidad del derrumbe hizo creer en un principio que se trataba de un forro de tapial que rodeaba a la torre de mampostería (Torremocha, 2004, p. 116). Esta excavación ha permitido comprobar, sin embargo, la existencia de una primera línea de barbacana inédita, a la que nos referimos en el segundo apartado.

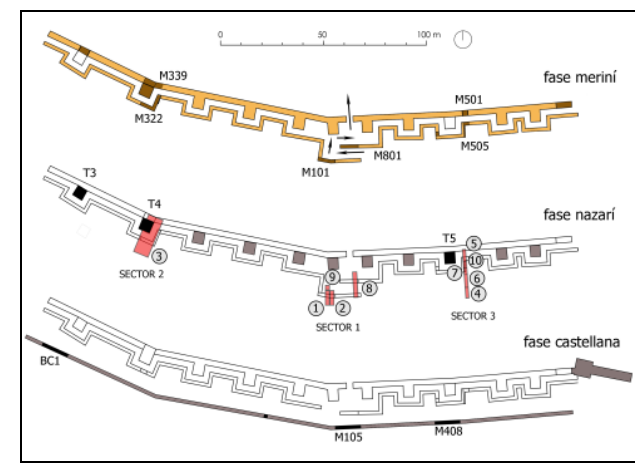

Fig. 12. Síntesis de las fases constructivas descubiertas en el tramo excavado en la Huerta del Carmen: meriní (muralla, primera barbacana y ¿puerta?), nazarí (torres) y castellana (barbacana exterior). Muros encofrados: trazado hipotético, en amarillo, y restos emergentes o excavados, en marrón. Obra de calicanto: trazado hipotético, en gris, y restos emergentes o excavados, en negro. En la fase nazarí, se han identificado en rojo los sondeos excavados y su numeración se ha rotulado dentro de un círculo.

\section{Conclusiones}

Se presenta el estudio de un tramo del sistema defensivo urbano de al-Binya o al-Bunayya. Ésta es la primera excavación que se realiza después de que hayamos descubierto que los vestigios pertenecen realmente a esta ciudad y no a la de al-Ŷazīra al-jadrā', la otra medina islámica localizada en Algeciras, con la que hasta ahora se habían confundido sus restos. También después de la presentación de nuevos presupuestos sobre la evolución de este sector amurallado (Jiménez-Camino, 2016) que corrigen anteriores propuestas cronológicas que situaban la construcción de los diferentes elementos defensivos en época emiral, almorávide o almohade (Torremocha Silva, 2004; Marcos Cobaleda, 2017).

En esta fortificación se aprecian tres programas constructivos, uno realizado con tapiales en época meriní (1282-1285) y dos realizados con mampostería y calicanto: uno en época nazarí (1312-1329 ca.) y otro en la castellana (1356 ca.1369), antes de que la ciudad fuera destruida y abandonada tras un último período de ocupación nazarí (1369 a 1375 o 1379), lo que permite otorgar a todas las obras una cronología cerrada entre 1282 y 1379 . En el sector estudiado se identifican: la muralla, dos barbacanas concén- 
tricas - la exterior ataluzada- y restos de estructuras de lo que podría ser una puerta de la ciudad, aunque esta última hipótesis está aún por confirmar.

\section{Bibliography}

Acién, M. (1999). "Los Ţugūr del reino nazarí. Ensayo de identificación", in Bazzana, A. dir., Castrum 5. Archéologie des espaces agraires méditerranéens au Moyen Âge. Actes du colloque de Murcie (Collection de l'École française de Rome 105/5), École française de Rome Ed., Roma, pp. 427-438.

Gentil Govantes, P. (1989). El riesgo sísmico de Sevilla, Tesis Doctoral, Universidad de Sevilla Ed., Sevilla.

Gómez de Avellaneda, C. (2018). "Gibraltar, causa de la destrucción de Algeciras en el siglo XIV y la verdadera fecha de ésta", Almoraima. Revista de Estudios Campogibraltareños, 48, pp. 101-114.

González, R.; Aguilar, L. (2011). El sistema defensivo islámico de Jerez de la Frontera. Fuentes para su reconstrucción virtual, Fundación Ibn Tufayl de estudios árabes Ed., Almería.

Jiménez-Camino, R. (2016). "Al-Bunayya, la manșūra de Algeciras. La fortificación de una ciudad meriní durante la Batalla del Estrecho (1275-1350)", in Teixeira, A. dir., Entre les deux rives du Détroit de Gibraltar: Archéologie de frontières aux 14-16e siècles, C.H.A.M. Universidade Nova de Lisboa (Colección Arqueoarte, 5) Ed., Lisboa, pp. 221-273.

Jiménez-Camino, R.; González, R.; Eïd, A.; Ramos, M.A.; Blanco, E. (2019). "Excavación arqueológica en el sistema defensivo de la ciudad meriní de al-Bunayya (Algeciras, 1282-1379 d.C.): primeros resultados" in V. Martínez, F. Siles. ed., Actas II Congreso internacional de historia de la Serranía de Ronda. Entre al-Ándalus y los inicios de la Edad Moderna (siglos VIII-XIV). Ronda, 2017, La Serranía Ed., Ronda.

Jiménez-Camino, R.; Tomassetti, J.M. (2006). "Allende el río... Sobre la ubicación de las villas de Algeciras en la Edad Media: una revisión crítica”, Almoraima, 33, pp. 183-210.

Marcos Cobaleda, M. (2017). "Restos materiales del papel de Algeciras en la conquista almorávide de al-Andalus", in Millán, A.; Aguilar, A.; Tente, C. eds., I Jornadas Internacionais de Idade Média "O papel das pequenas cidades na construçao da Europa medieval". Castelo de Vide, 2016, Instituto de Estudos Medievais Ed., Lisboa, pp. 161-176.

Pavón Maldonado, B. (1996). "Planimetría de ciudades y fortalezas árabes del norte de África. Murallas, torres y puertas. Estado de la cuestión y avances", Cuadernos del Archivo Municipal de Ceuta, 9, pp. 17-162.

Tomassetti, J.M.; Jiménez-Camino, R. (2012). "Cartografia histórica de al-Bunayya: imágenes de la ciudad meriní de Algeciras", Aljaranda. Revista de Estudios Tarifeños, 84, pp. 28-47.

Tomassetti, J.M.; Jiménez-Camino, R.; Perles, B. (2013). "Epígrafes góticos en la muralla de al-Yazirat al-Jadra (Algeciras, España)", in Fernandes, I.C.F. coord., Fortificações e Território na Península Ibérica e no Magreb (séculos VI a XVI), Edições Colibri Ed., Lisboa, vol. II, pp. 837-843.

Torremocha, A.; Navarro, I.; Salado, J.B. (1999). Al-Binya, la ciudad palatina meriní de Algeciras, Fundación Municipal de Cultura "José Luis Cano" Ed., Algeciras.

Torremocha Silva, A. (2004). "Fortificaciones almohades en la provincia de Cádiz", in Valor, M.; Villar, J.L.; Ramírez, J. coords., Los Almohades, su patrimonio arquitectónico y arqueológico en el sur de al-Andalus, Consejería de Relaciones Internacionales Ed., Sevilla, pp. 103-122. 